\title{
Erratum to: Some Biological Effects of the Fruits and Leaves of Different Apple Cultivars, Including Red-Fleshed Apples, Grown in a Microclimatic Region of Turkey: Part I
}

\author{
Nurcan Erbil ${ }^{-}$Mehmet Arslan ${ }^{1} \cdot$ Zehra Tugba Murathan $^{2} \cdot$ Ahmet Ilcim $^{3} \cdot$ Bilge Sayin Borekci $^{4}$ \\ Published online: 18 November 2020 \\ ○) Springer-Verlag GmbH Deutschland, ein Teil von Springer Nature 2020
}

\section{Erratum to:}

Erwerbs-Obstbau 2020

https://doi.org/10.1007/s10341-020-00527-5

The original version of this article unfortunately contained a mistake.

The address of Bilge Sayin Borekci was incorrect. The correct version is given above.

The acknowledgement was missing. The acknowledgement is given below.

Acknowledgements We wish thank The Scientific and Technological Research Council of Turkey (TUBITAK) for supporting our study through Project Grants No. $115 Z 833$.

The original article has been corrected.

The online version of the original article can be found under https://doi.org/10.1007/s10341-020-00527-5.

Nurcan Erbil

nurcanerbil@ardahan.edu.tr

1 Faculty of Health Sciences, Ardahan University, 75000 Ardahan, Turkey

2 Battalgazi Vocational School, Malatya Turgut Ozal University, 44210 Malatya, Turkey

3 Faculty of Arts and Sciences, Mustafa Kemal University, 31060 Hatay, Turkey

4 Faculty of Engineering, Ardahan University, 75000 Ardahan, Turkey 